\title{
Incidence of Mycotoxigenic fungi Associated with Decayed Saccharrum officinarum and the Effect of Chlopyriphos insecticide on their mycelia Growth and Glutamic-oxaloacetic acid Activity.
}

\author{
${ }^{*}$ Ojo, O.A, ${ }^{2}$ Olaniran, O.A and ${ }^{3}$ Adebayo T.A \\ ${ }^{1,2,3}$ Department of Crop and Environmental Protection, Ladoke Akintola University of Technology, Ogbomoso,
} Nigeria.

\begin{abstract}
Forty-six fungal species belonging to thirty genera were isolated from sixty samples of Saccharrum officinarum collected from Sabo Sugarcane market, Ogbomoso, Nigeria. Aspergillus, Trichoderma, Mucor and Pythium were the most common genera on the two isolation media. The dominant species of Aspergillus were A. niger, A. flavus, A. ustus, A. terreus and A. wentii. Some species were dominant on $60 \mathrm{~g} / \mathrm{l}$ sucrose such as Aspergillus niger, A. flavus, Emericella nidulans, Trichoderma viride, Torula herbarum and Mamaria echinoeotryoides, while the dominant species on $20 \mathrm{~g} / \mathrm{l}$ glucose were Mucor circinelloides, Aspergillus niger, Torula herbarum and Trichoderma viride. Mycotoxins including aflatoxins B1, B2, G1 and G2, zearalenone and diacetoxyscirpenol were detected in the examined samples of Saccharrum officinarum. The mycelial growth of

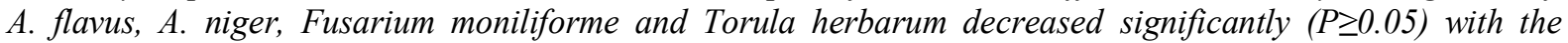
increase in Chlopyriphos concentrations, although 10 Part per millim (ppm) was less effective than the higher levels of the insecticide (50-250 ppm). Chlopyriphos stimulated the activity of Glutamic-oxaloacetic acid (Go-T) in A. flavus, F. moniliforme and T. harbarum, while the Go-T activity was inhibited in A. fumigatus with the Chlopyriphos treatments. The significant of the incidence of mycotoxigenic fungi associated with decayed samples of Saccharrum offioinarum and the effect of chlopyripos insecticide on their mycelia growth and Glutamic-oxaloacetic acid is herein discussed.
\end{abstract}

Keywords: Fungi, Mycotoxin, Saccharrum officinarum, Chlopyriphos

\section{Introduction}

Saccharum officinarrum is one of the most important crops in the world because of its strategic position and immense uses in the daily life of any nation as well as for industrial uses aimed at nutritional and economic sustenance. Sugarcane contributes about $60 \%$ of the total world sugar requirement while the remaining $40 \%$ came from sugar beet, ([1]. It is a tropical crop that usually takes between $8-12$ months to reach its maturity. Matured cane may be green, yellow, purplish or reddish considered ripe when sugar content is at its maximum $[2,3]$. The African in area and sugar production was estimated as 1.2 million hectares with 72.1 million metric tons, respectively [4]. The important sugar-producing countries in the tropical Africa are Mauritius, Kenya, Sudan, Zimbabwe, Madagascar, Cote d'Ivoire, Ethiopia, Malawi, Zambia, Tanzania, Nigeria, Cameroon and Zaire. Nigeria is one of the most important producers of the crop with a land potential of over 500,000 hectares of suitable cane field capable of producing over 3.0 million metric tons of sugarcane [2]. Sugarcane plant (Saccharum officinarum) is the predominant crop used in sugar production in savannah zone of northern Nigeria and it is been transported to different communities in South Western Nigeria. Sugar present in the stem of Saccharum officinarum represents the main source for fungal growth. Dare and Fawole Curei and Girot [3] studied the seasonal fluctuations of soil and root surface fungi of sugarcane in the savannah zone of northern Nigeria. They isolated 73 species and 5 varieties representing 33 genera using glucose-, cellulose-and sucrose-Czapek's agar media. Since some molds can produce toxic metabolites (mycotoxins), proliferation of the organisms represents a potential health hazard [6]. The occurrence of mold from sugarcane and sugarcane juice are also common. According to Almas et al., [7]. Cladosporium, Curvularia, Fusarium, Helminthosporium, Pestalotia and Phoma are found in sugarcane caryopses. In sugarcane the microbial contamination found were mainly yeast [8]. The distribution of Aspergillus flavus and A. parasiticus in sugarcane field soils and on harvested sugarcane stem s were studied by Takahasho et al., [9] who found that aflatoxin production were $89 \%$ in 146 of 164 and of all the isolates $69 \%$ were A. flavus isolates. Aflatoxin G was produced by $40 \%$ of A. flavus isolates. Aspergillus niger and A. flavus are the common allergens and may cause opportunistic invasive infections $[10,11] \mathrm{A}$. fumigatus is an ubiquitous mold and the most common cause of invasive aspergillosis in immune compromised patients [12]. Therefore, detection of fungal contaminants is essential to ensure safe and high quality food [13]. On the other hand, insecticides have been used to control insects and play a significant role in increasing crop production. They commonly affect some of the non-target organisms such as microbial 
population ranging from inhibitory to stimulatory effects [14]. Chlopyriphos is a broadspectrum insecticide and commonly used in sugarcane to control the white fly [15]. The effect of insecticides on fungal growth and enzymes activity has been studied by different workers $[16,17,18]$. Therefore the objective of the present study was to evaluate the occurrence of fungal Species and Mycotoxins from Decayed Sugarcane (Saccharrum officinarum) in Ogbomoso, Nigeria, as well as evaluate the effects of chlopyriphos insecticide on their mycelia growth and glutamic-oxaloacetic acid enzyme activity.

\section{Collection of Saccharrum officinarum Samples}

\section{Materials And Methods}

Sixty samples of (Saccharrum officinarum) stems were collected during two seasons (raining and dry 2013) from the Sabo sugarcane market, Ogbomoso, Oyo state, Nigeria. Each sample was represented by 15 decayed stem parts. The samples were transferred directly to the Pure and Applied Biology laboratory, Ladoke Akintola University of Technology, Ogbomoso, Nigeria for fungal isolation, while mycotoxin analysis was determined using the standard kit at laboratory of Institute of Agriculture Research and Training (IAR\&T) More plantation Ibadan, Nigeria.

\section{Isolation and identification of fungi from Saccherrum officinarum.}

The stem-samples were washed with sterilized distilled water. Each stem was cut into segments $(0.5$ $\mathrm{cm}$ long) by knife, and then each segment was cut into four equal parts. These segments were placed on the surface of two solidified media, glucose $(20 \mathrm{~g} / \mathrm{l})$ and sucrose $(80 \mathrm{~g} / \mathrm{l})$ Czapek's agar to which chloromphnicol was added as a bacteriostatic agent [19]. Five Petri plates of tested medium were used for each stem sample. Plates were incubated at $25 \mathrm{oC}$ for one week. For the recovery of aquatic fungi, stem segments from the collected samples were placed in Petri-dishes; $100 \mathrm{~mm}$ in diameter (6 replicates). The segments in each Petridish were then covered with sterile distilled water $(20 \mathrm{ml})$ and 12 sterilized sesame seeds were introduced into each Petri-dish, as employed by [19]. The growing fungi were identified, counted as numbers per segment. The identification of fungal genera and species was performed according to [20]. Fungal species recovered from stem samples were purified on suitable media such as glucose-peptone-agar, malt-extract-agar, potato-dextroseagar, potato-dextrose-yeast-agar, sabouraud's-dextrose-agar and Czapek's-medium.

\section{Mycotoxin extraction from Saccherrum officinarum.}

The mycotoxin extraction and cultification was done at Institute of Agriculture and Training (IAR\&T) Ibadan, Oyo state, Nigeria. Following the method of [18] Fifty grams of decayed stems of each sugarcane sample were transferred to $500 \mathrm{ml}$ Erlenmeyer flasks containing $150 \mathrm{ml}$ of chloroform each and placed in a shaker (200 rpm) for 16 hours, then filtered through filter paper (Whatman No. 1). The chloroform extract was dried over anhydrous sodium sulphate. The remaining stem samples were dried at $50^{\circ} \mathrm{C}$ over night, followed by re-extraction by $150 \mathrm{ml}$ of $90 \%$ methanol-water. Chemical detection of mycotoxins. Thin layer chromatography (TLC) technique was carried out using precoated with Silica Gel type 60, F254 (MERCK, Germany). Aflatoxins B1, B2, G1 \& G2; ochratoxins A \& B; sterigmatocystin; citrinin; T-2 toxin; diacetoxyscirpenol (DAS); zearalenone; moniliformin and fusarin $\mathrm{C}$ were used as standards. The developing solvent systems used were methanol - chloroform (v/v $3: 97)$, ethyl acetate-hexane (v/v, $70: 30)$, ethanol - chloroform (v/v, $5: 95)$ and toluene - acetone - methanol (v/v/v, $50: 30: 20)$. The developed plates were then viewed under UV light (254 and/or $366 \mathrm{~nm}$ ) and sprayed with reagents for identification according to [21].

\section{Determination the Effect of Chlopyriphos Insecticide on Mycelial Growth and Glutamic- oxaloacetic transaminase.}

The effect of the insecticide Chlopyriphos on mycelial growth and glutamic-oxaloacetic transaminase (Go-T) activity were studied using most commonly occurring fungal species namely; Aspergillus flavus, A. niger, Fusarium moniliforme and Torula herbarum. Fifteen Erlenmeyer flasks $(250 \mathrm{ml})$, each containing $50 \mathrm{ml}$ Czapeck's-Dox liquid medium, were used for each fungus. Triplicate flasks served as control, in which media were amended with 10, 50, 150, 200 and 250 (part per million) of the chloropyriphos insecticide. Each flask was inoculated with $1 \mathrm{ml}$ of the spore suspension obtained from seven days old cultures (Czapeck's-Dox medium) of the required fungus. The flasks were then incubated at $27 \mathrm{oC}$ for seven days, after which the mycelial filtrates were collected from the flasks by Buchner filtration using hardened filter papers, washed several times with sterile distilled water and weighed glutamic-oxaloacetic transaminase (Go-T) was determine following the method of [22], in which ten milligrams of the fresh mycelia were mixed and homogenized with $1.0 \mathrm{ml}$ phosphate buffer. The extracts were clarified by centrifugation for $15 \mathrm{~min}$ at $8000 \times \mathrm{g}$ and then analyzed for Go$\mathrm{T}$ as described by [23] using the transaminases kit (Quimica Clinica Aplicada S.A.). 


\section{Results And Discussion}

The result on the fungi associated with decayed Saccharrum officinarum samples using glucose or sucrose as carbon source is presented in Table 1 and Fig. 1 . These results showed that numbers of fungi were greatest on $20 \mathrm{~g} / \mathrm{l}$ glucose medium than $80 \mathrm{~g} / \mathrm{l}$ sucrose medium, while, the number of species isolated on sucrose medium was more diverse than that recovered on glucose medium. In this respect, twenty-six species belonging to eighteen genera were collected from the forty samples of sugarcane on glucose-medium, while thirty-eight species belonging to twenty-six genera were collected on the sucrose-medium. A total of forty-six fungal species belonging to thirty genera were isolated from the sixty samples of sugarcane on both glucose and sucrose media during raining and dry seasons. Sixteen out of these species were isolated on both tested media, while ten species were obtained only on glucose medium and twenty-two species were isolated only on sucrose medium. The dominant genera on the two types of media were Aspergillus, Trichoderma, Mucor, Mammaria, Torula and Cephalosporium. Fungi recovered on glucose-agar medium. Twenty-six species belonging to eighteen genera were recovered from sixty decayed sugarcane samples in Sabo Market, Ogbomoso, Nigeria on glucose- Czapek's agar at $25^{\circ} \mathrm{C}$ (Table 1). Aspergillus was the dominant genus representing $95 \%$ of the samples constituting $45.8 \%$ of the total number of fungi. It was represented by seven species of which A. flavus $(8.78 \%)$, A. niger (30.4\%), and A. ustus (4.4\%) were of high occurrence. These Aspergillus species were also recovered from Saccharrum officinarum leaves, stem, bagasse and juice by $[24,26]$. The remaining Aspergillus species were of moderate to rare occurrence on $20 \sim 5 \%$ of the samples. These species namely, A. awamori $(1.1 \%$ of the total number of fungi), A. terreus $(0.6 \%)$, A. wentii $(0.4 \%)$ and A. japonicus $(0.2 \%)$. Trichoderma, Emericella, and Torula species were the second in occurrence. These were recovered from $85 \%, 75 \%$ and $90 \%$ of the tested samples and represented by high occurrence by $19.4 \%, 11.9 \%$ and $7.9 \%$ of the total fungal, respectively. Each was represented by one species namely, Trichoderma viride, Emericella nidulans and Torula herbarum. Colletotrichum dematium was of high occurrence, it appeared in $45 \%$ of the Saccharrum officinarum samples and constituted 3.93\% of the total fungal; this agrees with the result of Abdel-Hafez et al., [27]. Eurotium chevaliere, Mucor heimalis, Pythium intermedium and Pilobolus sp. were of moderate occurrence $(40 \%, 40 \%$, $30 \%$ and $35 \%$ of the samples) and constituted $1.5 \%, 1.4 \%, 1.3 \%$ and $1.8 \%$ of the total fungal population, respectively. Each of Gliomastix cerealis and Melanospora fallax were of low occurrence ( $20 \%$ of the samples), representing $1.0 \%$ and $0.6 \%$ of total fungi, respectively. The remaining species were of rare occurrence $(5 \sim 10 \%$ of the samples) constituting $0.7 \sim 0.1 \%$ of the total fungi. These species were Apodachlya brachynema, Achlya megasperma, A. americana, Allomyces macrogynous, Curvularia tetramera, Cunninghamella elegans, Moncilium mucidum, Synecephalostrum racemosum and Rhizopous stolonifer. Several researches reported that some strains of these fungi produced several toxic metabolites [28, 29]. Fungal genera and species recovered on sucrose agar. Thirty-six species belonging to twenty-four genera were recovered from sixty Saccharrum officinarum samples on $60 \mathrm{~g} / \mathrm{l}$ sucrose- Czapek's agar at $25^{\circ} \mathrm{C}$ (Table 1). Abdel-Hafez et al., [26] isolated fortysix species and two varieties belonging to twenty genera from sixthy Saccharrum officinarum juice samples on glucose-, sucrose- and cellulose-Czapek's agar at $28^{\circ} \mathrm{C}$. The dominant genera were Aspergillus (eight species), Trichoderma (one specie), Mucor (four species), Torula (two species) and Cladosporium (one specie). They occurred in samples at rates $0.5 \sim 85.0 \%$ of the total samples investigated. In this respect, Almas et al., [7] recorded that Aspergillus, Eurotium and Penicillium were the most common genera in dried fruits using $20 \%$ sucrose-Czapek's agar at $28^{\circ} \mathrm{C}$. These results almost agree with the findings of Megalla et al., [30] who noted that Aspergillus and Penicillium were the most common in tropical foodstuffs, respectively. The most dominant species were Aspergillus awamori, A. niger, A. ustus, A. flavus, A. versicolor, A. oryzae and A. terreus. Trichoderma ( $80 \%$ of the samples) was second to Aspergillus and was represented by one species namely, T. viride which constitutes $16.1 \%$ of the total count of the isolates. Mucor came third and it was represented by four species namely, M. circinelloides, M. heimalis, M. plumbeus, and M. racemosus constituting $0.2 \sim 7.6 \%$ of the total fungi recovered (Table 1). Torula was represented by two species namely, T. herbarum and T. grisea constituting $4.9 \%$ and $0.6 \%$ of the total fungi recovered, respectively. Cladosporium herbarum, Cunninghamella elegans, Saccharomyces spp., Fusarium moniliforme and Cephalosporium curtipes were of moderate occurrence, they comprised $1.25 \sim 3.49 \%$ of the total fungi recovered. The following genera namely, Curvularia tetramera, Mammaria echinoeotryoides, Penicillium luteum and Pythium intermedium were represented by low occurrence and constituting $1.1 \sim 2.3 \%$ of the total fungi recovered. The remaining genera and species were represented by rare occurrence $(5.0 \sim 10.0 \%)$; with a frequency of $0.1 \sim 0.8 \%$. Saccharomyces spp. appeared only on the sucrose medium. The result on the seasonal fluctuation of the fungal species is presented in Table 1 and Fig. 1. The result showed that twenty-six species appeared on glucose medium in both raining and dry seasons Table 1 and Fig. 1. The seasonal fluctuation of these species on glucose medium revealed that nine species appeared in dry, seven species in raining and ten species in both seasons Table 1 and Fig. 1. On the other hand, thirty-eight fungal species were recovered on sucrose medium in both raining and dry seasons Table 1 and Fig. 1. Nineteen species of them were isolated in winter, ten species in summer and nine species isolated in both seasons on sucrose medium. Generally, forty-six fungal species were recovered from the two seasons on the two 
tested media. Nineteen out of these species were isolated only in dry and twelve species were isolated only in raining, while seventeen species were isolated in both seasons. The result on visual estimation of mycotoxin production by some fugal associated with decay Saccharum officinarum samples is presented in Table 2. The result showed that Fusarium moniliforme produced zearalenone and diacetoxyscirpenol toxins. In addition These results were in agreement with those of Leitao et al., [31]. Fusarium was recorded as zearalenone producer in some tropical food [32,33]. Thin layer chromatography analysis revealed the significant amounts of aflatoxins B1, B2, G1 and G2 in the tested samples produced by A. flavus (Table 2). Thin layer chromatography analysis revealed the significant amounts of aflatoxins B1, B2, G1 and G2 in the tested samples produced by A. flavus (Table 2). These aflatoxins particularly B1 are associated with acute poisoning of animal and human [7], lack of appetite, weight loss, unthrifitness, neurological abnormalities, jaundice of mucous membrane, convulsions and death [33], causes damage of chromosomes [34] and carcinogenic for human liver [35]. Based on visual estimation, when the sugarcane samples were subjected to aflatoxin screening, A. niger, A. ustus and Emericella nidulans were not toxin producers. Similarly, the isolated Colletotrichum dematium was also not toxin producer. The result on fungi associated with Saccharrum officinarum sample are visual estimation of mycotoxin is presented in Table 2. Colletotrichum falcatum but not from healthy or wounded sugarcane. The result on the effect of different concentrations of the insecticide Chlopyriphos on mycelial growth and Go-T activity in A. flavus, A. fumigatus, F. moniliforme and T. harbarum is presented in Table 3. Generally, the growth of mycelium decreased significantly $(\mathrm{P} \geq 0.05)$ with the increase in Chlopyriphos concentrations in all tested fungi. Although $10 \mathrm{ppm}$ was less effective than the higher levels of the insecticide. Highly significant $(\mathrm{P} \geq 0.05)$ decrease in mycelial fresh weight was observed at 100 250 ppm of Chlopyriphos in all studied fungi, as compared with the control treatment. At low level $(10 \mathrm{ppm})$ of Chlopyriphos, mycelial growth decreased significantly $(\mathrm{P} \geq 0.05)$ in $\mathrm{F}$. moniliforme and $\mathrm{T}$. herbarum while the reduction in mycelial growth of $\mathrm{A}$. flavus and A. fumigatus did not statistically differ from the control treatment. The results revealed that the fungal growth decreased with the increase in pesticide concentrations, which is in agreement with Abd-Elaah [36] who found that Chlopyriphos sharply reduced the growth of Saprolegnia ferax, Achlya proliferoides and Dictyuchus sterilis. The effect of insecticides on the inhibition of mycelial dry weight of Aspergillus fumigatus and Fusarium moniliforme was also observed by Botelho and Moriteiro [37]. They reported that the rate of inhibition to be also influenced by the type of the fungus, age of the mycelium and concentration of the pesticides. The results indicated that the Chlopyriphos treatments stimulated the Go-T activity in A. flavus and inhibited it in A. fumigatus, as compared with the respective control values (Table 4). The activity of Go-T in F. moniliforme was higher than that of the control at $10 \sim 150 \mathrm{ppm}$ of the insecticide, while it was inhibited at the higher level $(250 \mathrm{ppm})$. In T. herbarum, the lowest level of Chlopyriphos (10 ppm) greatly stimulated the Go-T activity, while its activity decreased with the increase of Chlopyriphos concentration. The above results revealed that the insecticide Chlopyriphos stimulated the activity of Go-T in A. flavus, F. moniliforme and T. herbarum especially at low doses. The inhibitory effect was prominent in case of A. fumigatus, indicating that this fungus was more sensitive to this insecticide than the other tested fungi This findings therefore [17] suggest that microorganisms can develop the ability of degrade pesticides either by enzyme induction or by mutation.

[1] Onwueme, 1. C. and Sinha, T.D. (1999), "CTA - Field Crop Production in Tropical Africa". CTA, Wageningen, Netheflands, pp $401-411$

[2] Onwueme, LC. and Sinha T. D. (1993), "CTA — Field Crop Production in Tropical Africa". CTA, Wageningen, Netherlands .Pp401-411

[3] Girei A.A. and Giroh (2012); Analysis of the Factors affecting Sugarcane (Saccharum officinarum) Production under the Out growers Scheme in Numan Local Government Area Adamawa State, Nigeria; Journal of education and practice vol. 3, NO 8:195200

[4] Onwueme, I. C. (1978), “Crop Science: Tropical Agricultural Series”. Cessel, London, pp89-90

[5] Mohawed, S. M., Abdel Hafez, S. I. I., EL-Said, A. H. M. and Gherbawy, Y. A. M. H. 2001. Seasonal fluctuations of soil and root surface fungi of sugarcane (Saccharum officinarum L.) inUpper Egypt. Egyptian J. Microbiol. 34: 595-611.

[6] Chuku, E.C., D.N. Ogbonna, B.A. Onuegbu and M.T.V. Adeleke, 2008. Comparative Studies on the Fungi and Bio-Chemical Characteristics of Snake Gaurd (Trichosanthes curcumerina linn) and Tomato (Lycopersicon esculentus mill) in Rivers state, Nigeria. Journal of Applied Sciences, 8(1): 168-172.

[7] Almas, A; shahanaz, D and Marium, T. (2010). Mycoflora associated with sugarcane juice in Karachi city. Pakistan Journal of Botany, 42(4):2955 - 2962

[8] Milintawaisamai, N., S. Niamsanit, R. Maungmontri, W. Buttapeng, R. Kotrsri, A. Pliansinchai and P. Weerathaworn. 2009. Efficacy of dimethyl benzyl ammonium chloride and microbial contamination studies in a modern sugarcane milling unit in Thailand. Sugar Tech., 11(2): 208-212.

[9] Takahashi, H., H. Kamimura and M. Ichinoe. 2004. Distribution of Aflatoxin-producing Aspergillus flavus and Aspergillus parasiticus in sugarcane fields in the Southernmost Islands of Japan. Journal of Food Protection, 67(1): 90-95.

[10] De hoog, G.S., J. Guarru, J. Gene and M.J. Figueras. 2000. Atlas of Clinical fungi. Centralbureau voor Schimmel cultures, Mycopathologia, Utrecht, The Netherlands. pp. 159-160.

[11] Mau, K.A., R.A. Carter, F. Crippa, A. Wald and L. Correy. 2002. Epidemiology and outcome of mold infections in haematopiotic stem cell transplant recipients. Clin. Infect. Dis, 37: 909-917. 
[12] Komanduri. 2007. Effects of Aspergillus fumigatus gliotoxin and methyl prednsolone on human neutrophils. Implifications for the pathogenesis of invasive aspergillosis. Journal of Leukocyte Biology, 82: 839-848.

[13] Bullerman, L. B. 1979. Significance of mycotoxins to food safety and human health. J. Food Prot. 42: 65.

[14] Dare, M.O and Fawole, O.B (2009): In vitro effects of some pesticides on pathogenic fungi associated with legumes. Australian Journal Science 3(3): 173-177.

[15] Anonymous, A. 1989. Chlopyriphos. In Environmental Health Criteria, Vol. 90, pp. 1-85. WHO, Geneva.

[16] Ojo, O.A (2009): Antifungal activities of some plant extract against important seed borne pathogen of fusarium sp. Netherlands Journal of Seed Pathology, Vol. 105(2) 123-134.

[17] Audus, L. J. 2010. Microbiological breakdown of herbicides in soil. Pp 1-17. In: E. K. Woodford and G. R. Sagar, Eds. Herbicides and soil. Blackwell Sci. Publications Ltd., Oxford.

[18] Ojo, O.A. and Adebayo, T.A. (2010): Mycotoxin fungal species associated with store groundnut at the level of aflatoxin in infected samples in Minna, Market, Niger State. Journal of Sustainable Agriculture, Vol. 65 (1): 23-33,

[19] El-Nagdy, M. A. 1986. "Studies on freshwater fungi in Upper Egypt", Ph.D. Thesis. Bot. Dept. Fac. Of Science, Assiut University, Egypt.

[20] Lund, A. 1978. Occurrence of Saproleginiaceae in Danish soils. Nova Hedwigia 39: 377-395.

[21] Vesonder, R. F. 1986. Moniliformin produced by cultures of Fusarium moniliforme var. subglutinans isolated from swine feed. Mycopathologia 95: 149-163.

[22] Ismail, M. A. 1993. Degradative enzymes and fungal flora associated with the Egyptian foodstuff Int. Biodet. Biodeg. $31: 143-157$.

[23] Reitman, S. and Frankel, S. 1957. Amer. J. Clin. Pathol. 28: 56 - 63 (Cited from Biochemical Manual of Quimica Clinica Aplicada S.A., E43870 Amposta, Spain, 2000, Tansaminasas GOT/AST Y GPT/ALT, Metodo Reitman-Frankel Colorimetrico, Ref. 9994 81).

[24] Muhsin, T. and Abdul-Kader, M. 1995. Ecology of fungi associated with Phragmites australis in Iraq. Abhath Al-Yarmouk 4: 3150 .

[25] Abdel-Hafez, S. I., El-Said, A. H. and Gherbawy, Y. A. 1995. Mycoflora of leaf surface, stem, bagasse and juice of adult sugarcane (Saccharum officinarum) plant and cellulolytic ability in Egypt. Bull. Fac.Sci. Assiut Univ. 24: 113-130.

[26] Brinker, A. M. and Seigler, D. S. 1991. Isolation and identification of piceatannol as a phytoalexin from sugarcane. Phytochem. 30: 3229-3232.

[27] Megalla, S. E., Abdou, R. F. and Bagy, M. M. 1985. Fungal flora of Egyptian baladi bread with special reference to the mutagenic effect of their toxic metabolites. Mycopathologia 89: 35-41.

[28] Leitao, J., LeBars, J. and Bailly, J. R. 1989. Production of aflatoxin B1 by Aspergillus ruber Thom and Church. Mycopathologia 108: $135-138$.

[29] Abdel-sater, M. A. and Ismail, M. A. 1993. Ecological and enzymatic studies on fungi associated with Biscuits in Egypt. Int. Biodet. Biodeg. 31: 277-292.

[30] Basch, U. and Mircua, C. J. 1992. Toxin production by Fusarium species by Iram sugar beets and natural occurrence beets and beet fibers. Microbiol. 3233-3239.

[31] Odoemelam SA, Osu CI (2009). Aflatoxin B1 contamination of some edible grains marketed in Nigeria. E-J. Chem. 6(2): 308-314. Available online at hppt://www. E-journals.nets.

[32] Makun, H.A; Anjorin, S.T., Moronfoye, B; Adejo, F.O, Afolabi, O.A Fagbayibo, H, Balogun B.O and Surajudeen A.A (2010) Fungal and Aflatoxin contamination of some human food commodition in Nigeria. African Journal of Food science. Vol 4(4):127135

[33] Reddy, K.R; Saleh, B; Abbas, H.A; Abel, C.A and shier W.T (2009) An overview of mycotixin contamination in foods and its implications for human health. Toxin Review 29(1):3-26

[34] Chukuunda, F.A, Osakwe, J.A and Baraka, R.E (2013) Control of seed borne fungi of stored maize from Nigerian stored products research institute, port Harcourt. Research web pub vol. 1(2):18-21

[35] Abd-Elaah, G. A. 1993. Effect of some pesticides on aquatic fungi in river Nile. Ph.D. Thesis, Assiut University, Egypt.

[36] Botelho, A.A and Moriteiro, A.C (2011) Sensitivity of emtomopathogenic fungi to pesticides used in the management of sugarcane. 70(2):361-369

[37] Samir K.A and Yehya A.S (2010) Mycobiota Associated with Sugarcane (Saccharum officinarum L.) cultivars in Iraq. Jordan Journal of Biological Sciences. 3(4): 193-202 
Table 1: Fungi isolated from Decayed Saccharrum officinarum on $20 \mathrm{~g} / 1$ glucose and $80 \mathrm{~g} / 1$ sucrose Czapeck's agar media

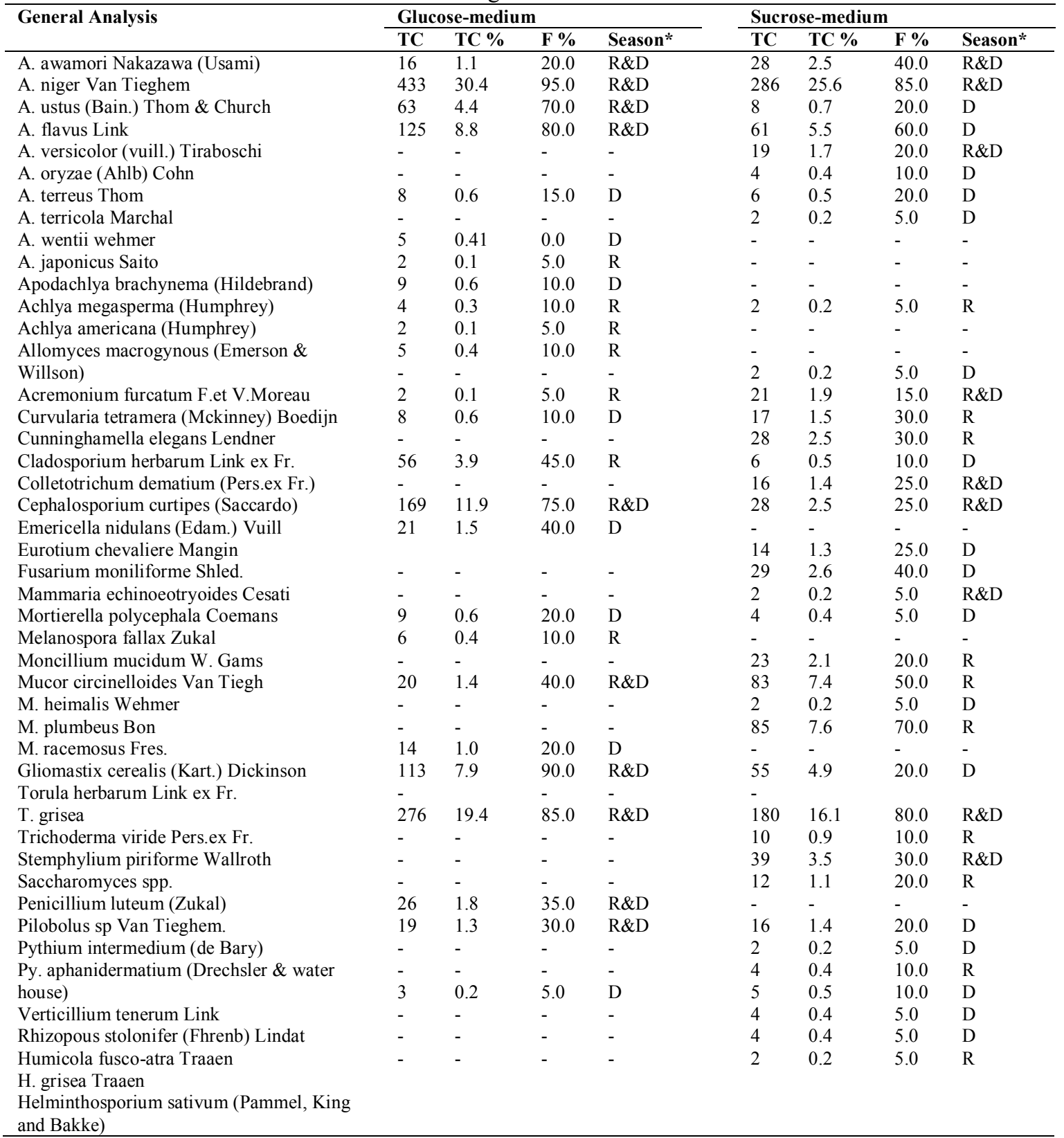

$\mathrm{TC}$ : total counts, $\mathrm{TC} \%$ : percentage of total counts, $\mathrm{F} \%$ : frequency of occurrence.

$* \mathrm{R}=$ Raining and $\mathrm{D}=$ Dry

- $\quad=$ Not Isolated 
Table 2: Visual estimation of mycotoxins in Saccharrum officinarum samples

\begin{tabular}{|c|c|c|c|c|c|c|c|c|}
\hline \multirow{3}{*}{ Fungal species } & \multicolumn{7}{|c|}{ Toxin production } & \\
\hline & \multicolumn{3}{|c|}{ Aflatoxins } & \multirow[b]{2}{*}{ G2 } & \multirow{2}{*}{\multicolumn{2}{|c|}{-Zearalenone }} & \multirow{2}{*}{ Diacetoxy-scripenol } & \\
\hline & B1 & B2 & G1 & & & & & \\
\hline Fusarium moniliforme & & & - & - & - & - & + & + \\
\hline Aspergillus flavus & & & + & + & + & + & - & - \\
\hline A. fumigatus & & & - & - & - & - & - & - \\
\hline A. solani & & & - & - & - & - & - & - \\
\hline Emericella nidulans & & & - & - & - & - & - & - \\
\hline Colletotrichum dematium & & & - & - & - & - & - & - \\
\hline
\end{tabular}

Table 3: The effect of different concentration of Chlopyriphos on mycelial growth on fungi associated with decay of Saccharrum officinarum

\begin{tabular}{lccccccc}
\hline & \multicolumn{7}{c}{ Mycelial weight of fungi (g) at Different rate (ppm) of chlopyriphos } \\
\cline { 2 - 7 } \multicolumn{1}{c}{ Name of pathogenic fungi } & $\mathbf{0 . 0}$ & $\mathbf{1 0}$ & $\mathbf{5 0}$ & $\mathbf{1 0 0}$ & $\mathbf{1 5 0}$ & $\mathbf{2 0 0}$ & $\mathbf{2 5 0}$ \\
\hline Aspergillus fumigatus & 4.50 & 03.10 & 02.60 & 02.00 & 01.60 & 01.20 & 1.00 \\
Aspergillus flavus & 6.00 & 4.83 & 03.71 & 03.41 & 02.41 & 02.00 & 01.50 \\
Aspergillus solani & 10.10 & 08.34 & 07.00 & 05.70 & 04.53 & 04.00 & 02.71 \\
Torula herbarium & 12.43 & 10.26 & 08.46 & 06.33 & 05.00 & 04.41 & 03.53 \\
LSD 0.05 & 01.11 & 01.18 & 01.00 & 01.13 & 0.08 & 0.03 & 0.02 \\
\hline
\end{tabular}

Table 4: Mycelial fresh weight and Glutamic-oxaloacitic acid (GO-T) content in the presence of different concentrations of Chlopyriphos

\begin{tabular}{|c|c|c|c|c|c|c|c|c|}
\hline \multirow{2}{*}{$\begin{array}{l}\text { Conc. } \\
\text { (ppm) }\end{array}$} & \multicolumn{2}{|c|}{ A. fumigatus } & \multicolumn{2}{|c|}{ A. flavus } & \multicolumn{2}{|c|}{ F. moniliforme } & \multicolumn{2}{|c|}{ T. herbarium } \\
\hline & $\begin{array}{l}\text { Fresh } \\
\text { weight } \\
(\mathrm{mg})\end{array}$ & $\mathrm{GOT} \mu / 1$ & $\begin{array}{l}\text { Fresh } \\
\text { weight } \\
\text { (mg) }\end{array}$ & $\mathrm{GOT} \mu / 1$ & $\begin{array}{l}\text { Fresh weight } \\
(\mathrm{mg})\end{array}$ & $\mathrm{GOT} \mu / 1$ & $\begin{array}{l}\text { Fresh } \\
\text { weight } \\
\text { (mg) }\end{array}$ & GOT $\mu / 1$ \\
\hline 0.0 & 4.1 & 14.0 & 5.7 & 8.0 & 8.0 & 8.0 & 7.2 & 14.0 \\
\hline 10 & 3.8 & $10.0^{* *}$ & 4.0 & 9.0 & $5.4^{*}$ & $11.0^{* *}$ & $4.7^{*}$ & $18.0^{* *}$ \\
\hline 50 & $2.6 * *$ & $10.0 * *$ & $3.1 * *$ & $11.0 * *$ & $4.3 * *$ & $9.5 *$ & $4.0 * *$ & $21.4^{*}$ \\
\hline 100 & $1.8 *$ & $9.0 * *$ & $2.0 * *$ & $14.5^{* *}$ & $2.3 * *$ & $9.5^{*}$ & $2.0 * *$ & $24.0 *$ \\
\hline 250 & $1.1 * *$ & $8.5^{* *}$ & $0.9 * *$ & 17.2 & $1.5 * *$ & 11.7 & $1.1 * *$ & $27 * *$ \\
\hline LSD 0.05 & 1.13 & 1.90 & 1.60 & 1.01 & 2.26 & 1.35 & 2.10 & 5.29 \\
\hline 0.01 & 1.48 & 2.49 & 2.10 & 1.32 & 2.96 & 1.77 & 2.75 & 6.93 \\
\hline
\end{tabular}

*, **: Significant and highly significant values as compared with the control treatment.

Table 5: The effect of Chlopyriphos on glutamic-oxaloacetic content of commonly occurring Fungi Associated with Decayed Saccharum officinarum.

\begin{tabular}{|c|c|c|c|c|c|}
\hline \multirow[t]{2}{*}{ Name of fungi } & \multicolumn{5}{|c|}{ GOT(Unit/Gfw) At Different Concentration of Chlopyriphos (ppm) } \\
\hline & 0.0 & 10 & 50 & 100 & 250 \\
\hline Torula herbarum & 15.03 & 18.11 & 21.78 & 24.00 & 27.89 \\
\hline Fusarium moniliforme & 15.61 & 17.30 & 19.36 & 22.00 & 24.76 \\
\hline Aspergillus fumigatus & 15.61 & 11.00 & 09.31 & 06.93 & 04.71 \\
\hline Aspergillus flavus & 15.00 & 20.03 & 23.38 & 27.88 & 30.50 \\
\hline LSD 0.05 & 00.02 & 00.71 & 0.04 & 0.03 & 0.05 \\
\hline
\end{tabular}




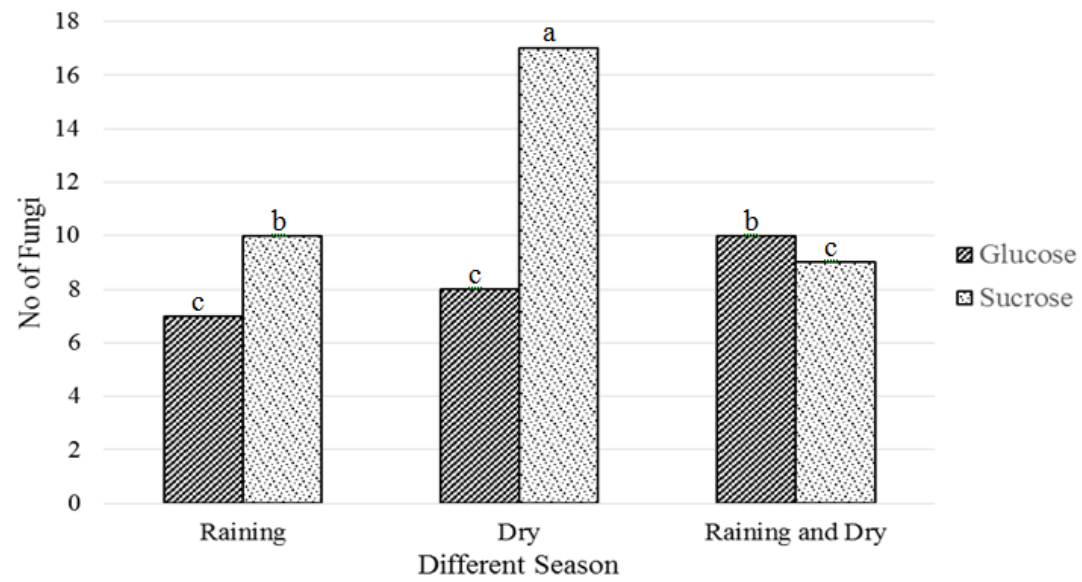

Data having similar alphabet are not significantly different at $5 \%$ level of probability using Duncan Multiple Range Test (DMRT)

Fig 1: Effect of Seasons on Numbers of Fungi Associated with Decayed Saccharrum officinarum 